\title{
Wine constituents inhibit thrombosis but not atherogenesis in C57BL/6 apolipoprotein E-deficient mice
}

\author{
Thierry Soulat ${ }^{1}$, Catherine Philippe ${ }^{2}$, Claire Bal dit Sollier ${ }^{1}$, Christophe Brézillon ${ }^{2}$, Natacha Berge ${ }^{1}$, \\ Pierre-Louis Teissedre ${ }^{3}$, Jacques Callebert ${ }^{4}$, Sylvie Rabot ${ }^{2}$ and Ludovic Drouet ${ }^{1} *$ \\ ${ }^{1}$ Laboratoire de Thrombose et d'Athérosclérose Expérimentales, IVS, Hôpital Lariboisière, 2 rue Ambroise Paré, 75475 Paris \\ Cedex 10, France \\ ${ }^{2}$ Unité d'Ecologie et Physiologie du Système Digestif, INRA, 78352 Jouy-en-Josas Cedex, France \\ ${ }^{3}$ Faculté d'Enologie, Université Victor Segalen Bordeaux 2, 351 cours de la Libération, 33405 Talence Cedex, France \\ ${ }^{4}$ Laboratoire de Biochimie, Hôpital Lariboisière, 2 rue Ambroise Paré, 75475 Paris Cedex 10, France
}

(Received 5 December 2005 - Revised 23 March 2006 - Accepted 29 March 2006)

\begin{abstract}
Regular and moderate wine consumption is one of the explanations suggested for the lower incidence of cardiovascular events in France compared with other industrialized countries. We evaluated whether alcohol alone or combined with red wine polyphenols reduced plaque size and/or attenuated thrombotic reactivity at the site of advanced atherosclerotic lesions. Red wine extract, or purified $(+)$-catechin with alcohol, or alcohol alone, was added for 12 weeks to the drinking water of apoE-deficient $\left(\mathrm{apoE}^{-1-}\right) \mathrm{C} 57 \mathrm{BL} / 6$ mice and wild-type counterparts. In the apoE ${ }^{-1-}$ mice, all alcohol-containing mixtures were associated with a larger size of aortic atherosclerotic lesions. On the other hand, red wine extract and $(+)$-catechin significantly inhibited blood thrombotic reactivity $(P<0 \cdot 05)$ as assessed in a cylindrical perfusion chamber model of experimental thrombosis: area reductions in cross-sectional surface of the ex vivo thrombus were $64 \%$ and $63 \%$, respectively. In the wild-type mice, red wine extract and (+)-catechin tended to reduce thrombogenicity, which was on the whole less marked than in the apoE ${ }^{-1-}$ mice. These findings suggest that a moderate and regular consumption of red wine may protect against clinical cardiovascular events, mainly by attenuating the thrombogenic response rather than by reducing the development of atherosclerotic lesions. This antithrombogenic effect may include normalization of the abnormally high thrombogenic responsiveness in ppoE $^{-/-}$mice as well as a direct antithrombotic effect.
\end{abstract}

Atherosclerosis: Thrombosis: Polyphenols: Alcohol: Apolipoprotein E-deficient mouse

\begin{abstract}
Atherothrombosis is the leading cause of death in industrialized countries (Murray \& Lopez, 1997). The clinical manifestations of atherothrombosis are ischaemic events due to the evolution/complication of atherosclerotic plaques and the thrombotic reaction onto these complicated atherosclerotic lesions. The 'French paradox' hypothesizes that the reduced incidence of cardiovascular manifestations of atherothrombotic disease in France and neighbouring Mediterranean countries is due, at least in part, to their cultural dietary features, mainly a regular and moderate consumption of wine, in comparison to Anglo-Saxon populations whose incidence of cardiovascular events is much higher for the same level of 'regular' cardiovascular risks (hypercholesterolaemia, hypertension, diabetes, etc.). Numerous experimental studies have been conducted to try to give grounds to this hypothesis, but most of them have focused on the potential anti-atherosclerotic effects of wine-derived polyphenols, based mainly on the antioxidant properties of these compounds and their influence on lipid metabolism (Hayek et al. 1997; Maor et al. 1997; Moghadasian et al. 1999). The potential antioxidant/anti-atherosclerotic benefit of wine polyphenols has
\end{abstract}

been extended to phenols of other origins such as green tea (Crespy \& Williamson, 2004; Sano et al. 2004; Vinson et al. 2004; Erba et al. 2005; Rah et al. 2005; Sung et al. 2005; Suzuki et al. 2005) and cocoa (Grassi et al. 2005; Keen et al. 2005; Kurosawa et al. 2005). Most of the animal studies have suspected a preventive effect of wine-derived phenols through their antioxidant activity, using very young animals before they had their first lesions and evaluating the beneficial effect as the prevention of lesion development (Hayek et al. 1997; Fuhrman et al. 2005). In man, intervention trials with antioxidant dietary compounds, mainly vitamins $\mathrm{E}$ and $\mathrm{C}$, have never sustained a protective cardiovascular effect of such a strategy. The main explanation evoked is that the animal studies focus strictly on prevention while human trials deal with already blown-up atherosclerosis. This specific issue was addressed using models of aged animals with evolved atherosclerosis (Bentzon et al. 2001), which did not find any beneficial effect, while most animal models using young animals with evolving pathology show a preventive effect of phenols (from wine and other origins). The animal model used in most of these experimental studies is based 
was measured every $2 \mathrm{~d}$ and body weight gain and food intake once a week.

Two weeks before the end of the experiment, six of the twenty-four mice in each group were placed in individual metabolism cages for daily individual collection of urine and faeces, which were stored at $-20^{\circ} \mathrm{C}$ until assayed. To protect the urine samples from bacterial contamination, $100 \mu \mathrm{l}$ of $0.4 \%$ sodium azide solution $\mathrm{v} / \mathrm{v}$ was added every day to the urine collection receptacles.

At the end of the experiment, the mice were killed by intraperitoneal injection of pentobarbital at a dose of $60 \mathrm{mg} / \mathrm{kg}$ body weight (Sanofi-Synthelabo, Le Plessis Robinson, France). After dissection, blood was drawn from the vena cava through a 25-gauge butterfly infusion set (Becton Dickinson, Le Pont de Claix, France) connected to an elastomer tube (Dow Corning, Midland, MI, USA) and a syringe pump (Harvard type 22; Ealing France, Les Ulis, France). The volume of blood that could be collected from a single mouse ranged from 500 to $1000 \mu$ l, which was not sufficient to allow determination of all the study variables in all animals. Therefore, in each treatment group, thrombotic reactivity and plasma LDL susceptibility to oxidation were each tested in six mice; plasma $(+)$-catechin concentration and antioxidant capacity were assayed in another six mice; and blood from the remaining six mice was used for platelet count and blood chemistry (plasma levels of cholesterol and triacylglycerols, activity of aspartate and alanine aminotransferases). Depending on the assay to be performed, the elastomer tube was filled with an anticoagulant agent $(10 \mu 1$ of $0.4 \mathrm{M}$-EDTA or $50 \mu \mathrm{l}$ of a heparin solution, $500 \mathrm{IU} / \mathrm{ml}$ ) prior to the blood collection. Platelets were counted in EDTA-anticoagulated blood using an MS4-CellDyn Analyser (Melet-Schloesing Laboratoires, Cergy-Pontoise, France); the blood was subsequently centrifuged $(1500 \mathrm{~g}$, room temperature, $10 \mathrm{~min})$ and the plasma was stored at $-80^{\circ} \mathrm{C}$ until chemistry assays. The heparin-anticoagulated blood collected for analysis of $(+)$-catechin and antioxidant status was centrifuged under the same conditions; plasma was then bubbled with $\mathrm{N}_{2}$ to avoid oxidation and stored at $-80^{\circ} \mathrm{C}$.

All procedures were carried out in accordance with European guidelines for the care and use of laboratory animals.

\section{Blood chemistry assays}

Plasma triacylglycerol and total cholesterol concentrations were determined using enzymatic methods on an AU800 analyser (Olympus, Rungis, France). The activities of aspartate aminotransferase and alanine aminotransferase were measured using standard methods to check that long-term consumption of alcohol did not induce liver damage.

\section{Analysis of $(+)$-catechin in plasma, urine and faeces}

Within each treatment group, the plasma samples from the sixmice subgroup intended for $(+)$-catechin analysis were pooled. After protein precipitation, $(+)$-catechin was analysed by HPLC using fluorescence detection as described by Carando et al. (1998).

For each of these mice, the faecal samples daily collected over the 2-week period in metabolism cages were pooled, freeze-dried, weighed and finely ground in an electric coffee grinder; extraction of $(+)$-catechin was carried out by thoroughly mixing $1 \mathrm{~g}$ faecal powder with $8 \mathrm{ml}$ sodium acetate buffer $(0.02 \mathrm{M}, \mathrm{pH} 4.0)$; suspensions were subsequently centrifuged $\left(8000 \mathrm{~g}, 4^{\circ} \mathrm{C}, 15 \mathrm{~min}\right)$ and supernatants were collected. Following thawing, urine samples were also pooled, then centrifuged $\left(1000 \mathrm{~g}, 4^{\circ} \mathrm{C}, 15 \mathrm{~min}\right)$, and the supernatants were acidified with one-fifth (v/v) of sodium acetate buffer. (+)Catechin was selectively extracted from urine supernatants and faecal extracts as described by Franke \& Custer (1994) using Sep Pak Plus C18 cartridges (Waters, Saint-Quentinen-Yvelines, France); extracts were concentrated to dryness by rotary evaporation and dissolved in $2 \mathrm{ml}$ sodium acetate buffer. Preliminary assays with urine and faeces spiked with $6.8 \mathrm{~mm}-(+)$-catechin showed that recovery was $97 \%$. Half of each extract was stored at $-20^{\circ} \mathrm{C}$; to allow measurement of glucuronidated and/or sulfated catechin, the other half was hydrolysed with $\beta$-glucuronidase and sulfatase from Helix pomatia type HP-2S (Sigma-Aldrich) as described by Franke \& Custer (1994).

Native and hydrolysed extracts were subsequently analysed for $(+)$-catechin content by HPLC (Waters). Samples (100 $\mu$ l) were injected with an autosampler 2690 onto a C18 reversephase column (LiChrospher ${ }^{\circledR} 100 \mathrm{RP}-18 \mathrm{e}, 250 \mathrm{~mm} \times 4 \mathrm{~mm}$, $5 \mu \mathrm{m}$; Merck, Paris, France) fitted with a LiChroCART ${ }^{\circledR}$ cartridge ( $4 \mathrm{~mm} \times 4 \mathrm{~mm}, 5 \mu \mathrm{m}$; Merck). Separation was achieved at a flow rate of $1.0 \mathrm{ml} / \mathrm{min}$ by gradient elution, using ultrafiltered water with $0.025 \%$ trifluoroacetic acid added as solvent $\mathrm{A}$ and methanol with $0.025 \%$ trifluoroacetic acid v/v added as solvent $\mathrm{B}$. The gradient programme was: 10 to $15 \% \mathrm{~B}, 0$ to $30 \mathrm{~min} ; 15 \% \mathrm{~B}, 30$ to $40 \mathrm{~min} ; 15$ to $30 \% \mathrm{~B}, 40$ to $110 \mathrm{~min}$; $30 \% \mathrm{~B}, 110$ to $120 \mathrm{~min} ; 30$ to $10 \% \mathrm{~B}, 120$ to $125 \mathrm{~min}$. (+)Catechin was monitored at $280 \mathrm{~nm}$ using a photodiode array detector 996. Data were collected and peaks integrated using the Millenium ${ }^{\circledR}$ software (version 4.0; Waters); quantification was achieved by comparing the peak areas with those of authentic standards spiked from 10 to $1000 \mu \mathrm{M}$.

\section{Antioxidant status}

Plasma antioxidant capacity. Plasma antioxidant capacity was measured using the total antioxidant status (TAS) method of Randox (Randox Laboratories, Crumlin, UK).

LDL susceptibility to oxidation. Within each treatment group, the plasma samples from the six-mice subgroup intended for analysis of LDL oxidation were pooled. Plasma LDL was separated by sequential density ultracentrifugation as previously described (Aviram, 1983). The LDL fraction was then dialysed for $24 \mathrm{~h}$ against PBS (without EDTA) to remove heparin. The protein content was determined using the method of Lowry et al. (1951) and adjusted to $100 \mu \mathrm{g}$ protein/ml with PBS. LDL oxidation was induced by adding $\mathrm{CuSO}_{4}$ at a final concentration of $5 \mu \mathrm{mol} / \mathrm{l}$. Conjugated diene formation was monitored at $234 \mathrm{~nm}$ using a DU640 spectrophotometer (Beckman, Gagny, France). Absorbance at the beginning of the reaction was set to zero. Lag times were determined graphically as the time points at which the tangent to the curve at the propagation phase peak intercepted the time axis.

Nitrate:nitrite ratio. NO production was assessed indirectly by determination of the nitrate:nitrite ratio in the 
urine of six mice per treatment group, using the method of Giovannoni et al. (1997).

\section{Ex vivo thrombogenic reactivity}

Ex vivo thrombogenic reactivity was assessed with the perfusion chamber model used in our laboratory (Andre et al. 1996) and adapted to studies in mice. A 25-gauge butterfly set (Becton Dickinson) inserted into the vena cava was connected to a syringe pump that was used to draw blood through the cylindrical perfusion chamber consisting of a calibrated glass tube (length $32 \mathrm{~mm}$, inner diameter $0.35 \mathrm{~mm}$ ) whose inner surface was uniformly coated with human type III collagen (final density $2.5 \mu \mathrm{g} / \mathrm{cm}^{2}$; Sigma-Aldrich). The uniformity of the collagen deposit and its resistance to disruption by blood flow were checked before the experiment. By modifying the flow rate of the pump, this set-up can reproduce the shear rate characteristics of various normal and diseased blood vessels; shear rate is the haemorheological parameter with the greatest influence on thrombus formation. In the present experiment, the shear rate was set to $1000 \mathrm{~s}^{-1}$, which is characteristic of arteries with moderate stenosis. After $2 \mathrm{~min}$ of perfusion of native blood through the chamber, the thrombotic deposit was rinsed, fixed, and embedded in Epon epoxy resin (Sigma-Aldrich, Saint-Quentin Fallavier, France). A microtome (Leica, Rueil-Malmaison, France) was used to cut $4-\mu \mathrm{m}$ sections perpendicularly to the direction of blood flow, $5 \mathrm{~mm}$ from the proximal part of the perfusion chamber.

\section{Aortic tissue processing}

After blood collection from the vena cava, the aortic tree was fixed by infusion with $2.5 \%$ glutaraldehyde $\mathrm{v} / \mathrm{v}$ in $0.1 \mathrm{M}$ sodium cacodylate buffer, $\mathrm{pH} 7 \cdot 4$, using a 5 -ml syringe inserted into the left ventricle. In apoE ${ }^{-1-}$ mice, the aortic arch region, with the valves and branch points of the two main arterial trees, is the site most susceptible to atherosclerosis (Tangirala et al. 1995b; Johnson \& Jackson, 2001). Therefore, for comparative histomorphometric studies of atherosclerotic lesion development, atherosclerosis was quantified at three predetermined locations of the aortic arch: (i) at the proximal aorta and (ii) above and (iii) below the start of the brachiocephalic trunk. The aortic arch was dissected free from the surrounding fatty tissue, then fixed and embedded as for thrombotic deposits (Andre et al. 1996). At each of the three locations, the maximal lesion was identified under microscopic examination. At each of the three sites of maximal lesion, fifteen transverse sections $1 \mu \mathrm{m}$ in thickness were sequentially cut on a microtome (Leica, Rueil-Malmaison, France) and stained with alkaline toluidine blue and fuchsin red to provide optimal resolution.

\section{Computer-assisted morphometry}

Thrombotic deposit after ex vivo perfusion. After staining of semi-thin cross-sections of embedded thrombotic deposits, thrombogenesis was evaluated using an optical microscope $(10 \times$ magnification; Zeiss, Le Pecq, France) and the image analysis software Atherose ${ }^{\mathrm{TM}}$ (Microvision Instruments, Evry, France). The main criterion was the area $\left(\mu \mathrm{m}^{2}\right)$ of the thrombus cross-sectional surface, which is representative of the thrombus size.

Atherosclerotic lesions. Plaques were measured using the same computer-assisted image analysis system. Size criteria were thickness, expressed as the ratio of plaque thickness over media thickness, and circumference, expressed as the percentage of cross-sectional circumference covered by the plaque. For each mouse and for the three aortic arch locations, the individual values are the mean of the fifteen serial sections. The values at the three sites for each treatment mice are the mean of twenty-four mice.

\section{Statistical analyses}

Data are expressed as means and their standard errors ( $n 6$ to 24 , depending on the parameter). To test the effect of apoE gene deletion, we compared the wild-type mice drinking water with their apoE ${ }^{-l-}$ counterparts consuming the same drink, using Student's $t$ test. The effect of the experimental drinks was analysed separately in each mouse strain, using a one-way ANOVA. When ANOVA indicated significant differences, treatments were compared using the Newman-Keuls multiple comparison test. $P<0.05$ was considered statistically significant. Calculations were performed using the Statview ${ }^{\circledR}$ software (version 5.0; SAS Institute, Cary, NC, USA).

\section{Results}

Effect of genetic status and drink composition on body weight gain and food and drink intakes

Significant body growth was observed during the 12-week study period that was similar in both strains and independent of the drink they consumed. The overall weight gain averaged 8 (SE 0.7) g. However, mice receiving alcohol, CAT-alcohol and RWE-alcohol ate and drank less than control mice given water. The overall food intake was $5.9 \mathrm{~kg}$ in the groups of wild-type and apoE ${ }^{-1-}$ mice drinking water, v. 5.1, 5.2 and $5.3 \mathrm{~kg}$ in the counterpart groups drinking alcohol, CAT-alcohol and RWE-alcohol. In the wild-type mice, the overall drink consumption was 8.1 litres in the water group $v .7 .5$ litres in the alcohol and CAT-alcohol groups and 6.5 litres in the RWE-alcohol group. In a similar fashion, whereas water consumption in apoE $\mathrm{E}^{-/-}$mice reached 9.0 litres, it was only 8.4 litres in the alcohol and CAT-alcohol groups and 7.2 litres in the RWE-alcohol group. On the whole, reduced energy intake from food was counterbalanced by the energy supplied by alcohol $(23 \cdot 2 \mathrm{MJ} / \mathrm{l})$.

\section{Effect of genetic status and drink composition on blood haematology and biochemistry}

Platelet counts. Wild-type and apoE $\mathrm{E}^{-/-}$mice drinking water had similar platelet counts (Table 2). In wild-type mice, consumption of the alcohol drink was associated with a lower platelet count compared with the group drinking water. In apoE ${ }^{-1-}$ mice, those drinking RWE-alcohol had significantly more platelets than those drinking water, alcohol or CAT-alcohol.

Aminotransferase activities. Alanine aminotransferase and aspartate aminotransferase levels remained normal (data not 
Table 2. Effect of genetic status (wild-type and apoE-deficient, apoE ${ }^{-1-}$ ) and drink composition (water, alcohol, (+)-catechin (CAT)-alcohol and red wine extract (RWE)-alcohol) on blood haematology and biochemistry and plasma antioxidant capacity of the mice (Mean values with their standard errors*)

\begin{tabular}{|c|c|c|c|c|c|c|c|c|c|c|c|c|c|c|}
\hline & \multicolumn{3}{|c|}{ Platelets $\left(10^{9} / \mathrm{I}\right)$} & \multicolumn{3}{|c|}{ Total cholesterol (mм) } & \multicolumn{2}{|c|}{$\begin{array}{l}\text { Triacylglycerols } \\
\text { (mM) }\end{array}$} & \multicolumn{2}{|c|}{$\begin{array}{c}\text { TAS } \\
(\mathrm{TEAC}, \mathrm{mm})\end{array}$} & \multirow{2}{*}{$\begin{array}{l}\text { LDL } \\
\text { oxidation } \\
\text { (lag time, } \\
\text { min) }\end{array}$} & \multicolumn{3}{|c|}{$\begin{array}{c}\text { Nitrate: nitrite ratio } \\
(\mu \mathrm{mol} / \mathrm{mmol} \text { creatinine })\end{array}$} \\
\hline & Mean & $P$ & SEM & Mean & $P$ & SEM & Mean & SEM & Mean & SEM & & Mean & $P$ & SEM \\
\hline \multicolumn{15}{|l|}{ Wild-type mice } \\
\hline Water & $1079^{a}$ & & 84 & $2 \cdot 7^{\mathrm{a}}$ & & 0.1 & $0 \cdot 71$ & 0.10 & 0.45 & 0.06 & ND & $497^{a}$ & & 53 \\
\hline Alcohol & $683^{\mathrm{b}}$ & 0.0054 & 87 & $2 \cdot 2^{b}$ & 0.0092 & 0.2 & 0.58 & 0.14 & 0.58 & 0.03 & ND & $841^{\mathrm{b}}$ & 0.0057 & 86 \\
\hline CAT-alcohol & $871^{a, b}$ & & 97 & $2 \cdot 6^{a, b}$ & & 0.1 & 0.56 & 0.04 & 0.67 & 0.05 & ND & $781^{\mathrm{b}}$ & 0.0187 & 86 \\
\hline \multicolumn{15}{|l|}{$\mathrm{ApoE}^{-/-}$mice } \\
\hline Water & $947^{\mathrm{a}}$ & & 62 & $12 \cdot 4 \dagger$ & & $1 \cdot 1$ & 0.90 & 0.14 & $0.64 \dagger$ & 0.04 & $48 \cdot 7$ & $434^{\mathrm{a}}$ & & 56 \\
\hline Alcohol & $749^{a}$ & & 98 & $12 \cdot 9$ & & 1.4 & 1.09 & 0.17 & 0.69 & 0.08 & 53.6 & $1013^{\mathrm{b}}$ & 0.0001 & 104 \\
\hline CAT-alcohol & $722^{a}$ & & 121 & $16 \cdot 1$ & & $2 \cdot 6$ & 0.92 & 0.12 & 0.88 & 0.07 & 42.5 & $867^{\mathrm{b}}$ & 0.0008 & 80 \\
\hline RWE-alcohol & $1295^{\mathrm{b}}$ & & 117 & $16 \cdot 7$ & & 1.0 & 0.87 & 0.11 & 0.72 & 0.11 & 53.9 & $837^{b}$ & 0.0016 & 61 \\
\hline
\end{tabular}

TAS, total antioxidant status; TEAC, Trolox ${ }^{\circledR}$ equivalent antioxidant capacity; ND, not determined.

${ }_{a, b}$ Mean values within each strain group with unlike superscript letters were significantly different (ANOVA plus Newman-Keuls test): $P<0.05$ )

${ }^{*} n 5$ to 6 , except for the analysis of LDL oxidation for which the plasma samples from the six mice were pooled (for details, see Material and methods, $p$. 291).

Mean values were significantly different from those of the wild-type mice drinking water (effect of genetic status; Student's $t$ test): $† P<0 \cdot 05$.

shown), indicating that the alcohol intake did not induce any noticeable lysis of hepatocytes.

Plasma cholesterol and triacylglycerol levels. As reported consistently with apoE ${ }^{-1-}$ mice (Plump et al. 1992), a severe hypercholesterolaemia occurred in this strain compared with its wild-type counterpart (Table 2). Among wild-type mice, those given the alcohol drink had a lower plasma cholesterol level than those given water only, whereas no difference was found for the groups given CAT-alcohol or RWE-alcohol. Among apoE ${ }^{-/-}$mice, drink composition had no influence on plasma cholesterol levels. With regard to plasma triacylglycerols, a trend towards higher concentrations was observed in apoE $\mathrm{E}^{-1-}$ mice compared with their wild-type counterparts. On the other hand, within each mouse strain, plasma triacylglycerol levels were similar across treatment groups.

\section{$(+)$-Catechin concentrations in plasma, urine and faeces}

As expected, no $(+)$-catechin was detected in either the plasma or the urinary and faecal excreta of wild-type and $\mathrm{apoE}^{-/-}$mice given the water and alcohol drinks. In both strains, plasma $(+)$-catechin levels were similar in the groups given CAT-alcohol and RWE-alcohol: 114.4 and $96.4 \mu \mathrm{g} / \mathrm{l}$ in the wild-type mice and 94.4 and $102.8 \mu \mathrm{g} / \mathrm{l}$ in the $a p o \mathrm{E}^{-1-}$ mice, respectively. However, neither free nor glucuronidated/sulfated $(+)$-catechin could be detected in the urine and faeces of mice given CAT-alcohol or RWEalcohol, regardless of the strain.

\section{Effect of genetic status and drink composition on antioxidant status}

Plasma antioxidant capacity. As previously reported, plasma TAS was low in both mouse strains compared with values found in human subjects (Diaz et al. 1998). Among mice drinking water, the apoE $\mathrm{E}^{-/-}$animals had higher TAS levels than their wild-type counterparts (Table 2). In neither strain did the alcohol-containing drinks affect plasma TAS levels.

LDL susceptibility to oxidation. No noticeable differences were observed between the LDL oxidation lag times measured in the apoE ${ }^{-1-}$ mice, whether they drank water or alcoholcontaining beverages (Table 2).

Nitrate:nitrite ratio. The nitrate:nitrite ratio was similar in the apoE $\mathrm{E}^{-1-}$ and wild-type mice drinking water (Table 2). In both strains, consumption of alcohol-containing drinks was associated with significantly higher nitrate:nitrite ratios compared with water consumption, although this difference was only a trend in the wild-type mice given the RWE-alcohol drink.

\section{Effect of genetic status and drink composition on thrombogenic reactivity}

The thrombus size, as assessed by the area of the thrombus cross-sectional surface, tended to be greater in apoE ${ }^{-1-}$ mice drinking water compared with their wild-type counterparts consuming the same drink. Among wild-type mice, the thrombus size was similar across treatment groups. In contrast, among apoE ${ }^{-1-}$ mice, the CAT-alcohol and RWE-alcohol drinks significantly reduced thrombus size, while the alcohol drink remained ineffective (Fig. 1).

\section{Effect of genetic status and drink composition on atherosclerotic lesions}

As expected, no atherosclerotic lesions were found in the wildtype mice. Among the apoE $\mathrm{E}^{-/-}$mice, the thickness and extent of the aortic arch atherosclerotic lesions, observed above the root of the brachiocephalic trunk, were significantly greater in animals consuming the alcohol-containing drinks than in those consuming water only (Fig. 2); this increase in lesion size was not significantly affected by phenolic compounds. In the proximal aorta and below the root of the brachiocephalic 


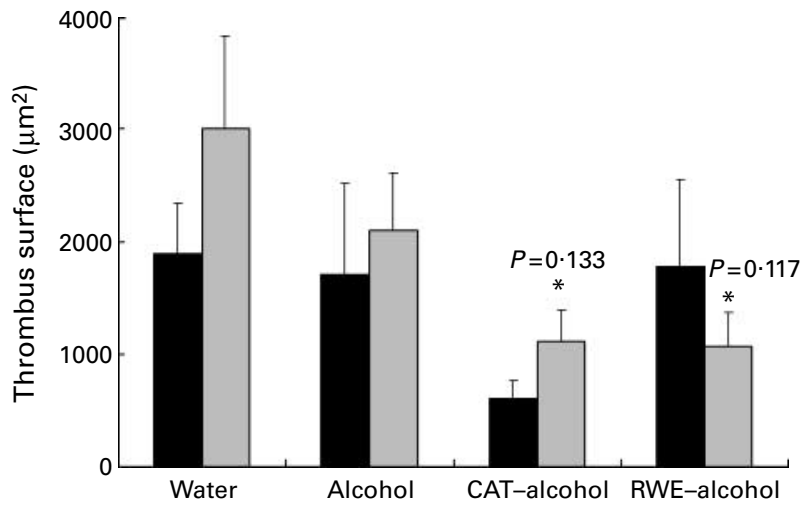

Fig. 1. Effect of genetic status ( $\square$, C57BL/6J wild-type mice; $\square$, C57BL/6J apoE-deficient mice) and drinking composition (water, alcohol, (+)-catechin (CAT)-alcohol, red wine extract (RWE)-alcohol) on ex vivo thrombus reactivity in a perfusion chamber assessed by the cross-sectional surface area of the thrombus, which reflects thrombus size. Values are means with their standard errors shown by vertical bars for six mice per group. Mean values were significantly different from those of the same-strain group given water only (ANOVA): ${ }^{\star} P<0.05$.

trunk, plaque thickness and extent were similar across treatment groups. At the site of the aorta where lesions were observed, administration of alcohol, CAT-alcohol or RWEalcohol had no effect on vessel media thickness and inner circumference (Table 3 ).

\section{Discussion}

Our findings indicate that adding either purified $(+)$-catechin or red wine extract to the drinking water of genetically hypercholesterolaemic mice failed to alleviate the atherosclerotic plaque burden. These results are at variance with a substantial body of evidence from other models in mice (Emeson et al. 1995) and other species (Goto et al. 1974; Klurfeld \& Kritchevsky, 1981; da Luz et al. 1999; Yamakoshi et al. 1999), but agree with a study by Munday et al. (1999) as well as with work by Bentzon et al. (2001) in the same mouse model. In the present study, alcohol-containing drinks increased the extent of the atherosclerotic lesions, regardless of their phenol content. The potential pro-atherogenic effect of alcohol observed in our mice is consistent with data from diet-induced atherosclerosis in rabbits (Shaish et al. 1997). Atherosclerosis is usually associated with oxidative stress characterized by a reduction in endogenous antioxidant capacity (Oemar et al. 1998). In models that showed chemoprevention by wine polyphenols against atherosclerosis, this effect was related to variously measured biomarkers of antioxidant status (Hayek et al. 1997). In the present study, neither phenols nor alcohol had any in vivo antioxidant effects detectable by the TAS assay or the LDL oxidation assay. Apart from wine phenols, various antioxidants are reported to protect against atherosclerosis (Meagher \& Rader, 2001) although the effects are not consistent with the various types of antioxidant. Thus, vitamin E (Pratico et al. 1998) or $N, N^{\prime}$-diphenyl1,4-phenylenediamine (Tangirala et al. 1995a) reduced atherosclerotic lesions in apoE $\mathrm{E}^{-/-}$mice, whereas probucol, another compound with antioxidant effects in the same animal model, was pro-atherogenic (Zhang et al. 1997). Thus, it remains unclear whether the effects of these agents
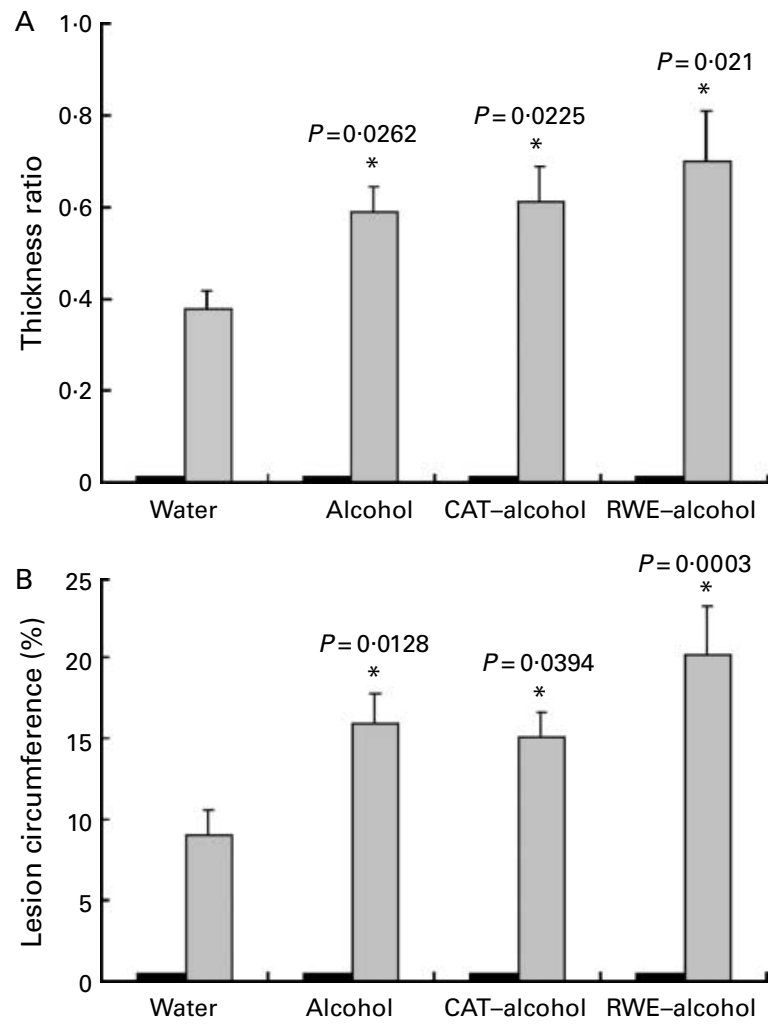

Fig. 2. Effect of genetic status ( $\square$, C57BL/6J wild-type mice; $\square$, C57BL/6J apoE-deficient mice) and drinking composition (water, alcohol, (+)-catechin (CAT)-alcohol, red wine extract (RWE)-alcohol) on atherosclerotic lesions in the aortic arch at the root of the brachiocephalic trunk, as assessed by (A) thickness ratio and (B) inner circumference (\%). Values are means with their standard errors shown by vertical bars for fifteen serial sections from each of six mice per group. Mean values were significantly different from those of the same-strain group given water only (ANOVA): ${ }^{\star} P<0.05$.

on atherosclerotic lesions are ascribable to their antioxidant properties.

NO production is usually believed to exert beneficial effects on cardiovascular physiology through its vasodilating, antihypertensive and antithrombotic effects. Reactive oxygen species would reverse this effect by interacting with NO to produce peroxynitrates, which can cause oxidative damage to the endothelium (Lopez-Jaramillo \& Casas, 2002). The antioxidant effect of wine phenols could prevent this potentially deleterious effect. Additionally, Andriambeloson et al. (1998) reported that wine polyphenols induced a direct vessel relaxation, but this was shown in an in vitro experiment in which relaxation of the rat aorta precontracted by noradrenaline was measured when various concentrations of polyphenols were added to the organ bath. These data were confirmed in a more recent study, in which endothelial cells exposed to red wine polyphenolic extract released NO in a concentration-dependent manner (Leikert et al. 2002). In the present in vivo study, measurement of the nitrate:nitrite ratio indicated an increase of endogenous NO production in both mice strains following the consumption of alcoholcontaining drinks. However, this effect was more probably related to alcohol rather than phenols, as most of the effect occurred with alcohol alone. Despite the effect on 
Table 3. Effect of drink composition (water, alcohol, (+)-catechin (CAT)-alcohol and red wine extract (RWE)alcohol) on the inner circumference and media thickness at the origin of the brachiocephalic trunk from the aortic arch in apoE-deficient mice

(Mean values with their standard errors*)

\begin{tabular}{|c|c|c|c|c|c|c|c|c|}
\hline & \multicolumn{2}{|c|}{ Water } & \multicolumn{2}{|c|}{ Alcohol } & \multicolumn{2}{|c|}{ CAT-alcohol } & \multicolumn{2}{|c|}{ RWE-alcohol } \\
\hline & Mean & SE & Mean & SE & Mean & SE & Mean & SE \\
\hline Inner circumference $(\mu \mathrm{m})$ & 2986 & 66 & 3088 & 68 & 3037 & 83 & 3000 & 59 \\
\hline Media thickness $(\mu \mathrm{m})$ & $67 \cdot 2$ & $2 \cdot 4$ & $66 \cdot 3$ & 1.5 & 63.3 & $2 \cdot 8$ & $67 \cdot 6$ & $2 \cdot 1$ \\
\hline
\end{tabular}

* $n 13$ to 17

No significant differences were observed across treatment groups.

NO production, addition of alcohol and phenols to drinking water failed to modify parameters reflecting vessel contraction and relaxation, such as arterial vessel diameter or vessel wall thickness.

Two strategies of chemoprotection against atherosclerosis can be investigated in the apoE $\mathrm{E}^{-1-}$ model: treatment early in life to prevent the development of atherosclerotic lesions, or curative treatment started later in life of animals that already have developed atherosclerosis. In this latter strategy, treatment effects are inferred from changes in the atherosclerotic lesions present at baseline. Overall, the data reported in this field suggest that wine polyphenols may be effective in preventing the development of atherosclerosis but not in alleviating the burden of established atherosclerotic lesions (Bentzon et al. 2001). In the present experiments, the aortic arch specimens taken above the root of the brachiocephalic trunk after a 12-week consumption of water, alcohol or alcohol combined with polyphenols showed atherosclerotic lesions in all the apoE $\mathrm{E}^{-/-}$mice. Compared with lesions found in human subjects, the murine lesions resembled more fatty streaks than mature atherosclerotic plaques, whose characteristic features are fibrous tissue proliferation and a lipid core rich in cholesterol crystals. Maximal atherosclerotic lesion size was quantified at three sites of the aortic arch known to develop the maximal lesions in apoE ${ }^{-1-}$ mice (Tangirala et al. 1995b; Johnson \& Jackson, 2001). This quantification of the maximal lesion unveiled an increased lesion size with alcohol intake at only one of these three aortic sites, namely the one above the root of the brachiocephalic trunk. Lesion size at the other two aortic sites was not affected by the experimental drinks. The structure of the lesions seemed similar across the three sites and not affected by the experimental drinks. The discrepancy between our results and those describing a phenol-induced reduction of atherosclerotic lesions in $a_{0 .} E^{-1-}$ mice (Hayek et al. 1997; Fuhrman et al. 2005) could be due to their expression of the results as the mean of all the lesions, without distinction between each of the individual locations of the aortic arch developing lesions, and our expression of lesion size focusing on maximal size.

The 'French paradox' is a way to express the unexpectedly lower rate of clinical cardiovascular events in France compared with populations with similar cardiovascular risk factors in Northern European and Anglo-Saxon industrialized countries. One possible explanation is that cultural differences in diet and wine consumption may influence the ischaemic cardiovascular event rate via an effect on atherogenesis and/or the thrombotic response to atherosclerotic lesions. To reflect the possible contribution of these two factors, the term 'atherothrombosis' is better adapted - from a pathogenic point of view - to designate the cardiovascular lesions responsible for ischaemic events. So far, the potential effect of polyphenols and alcohol on thrombus formation has received far less attention than effects on atherogenesis, and few reports come from studies focusing on arterial thrombosis (Demrow et al. 1995; de Gaetano et al. 2002). In most of them, polyphenols reduced the thrombotic response via an effect on platelets (Osman et al. 1998; Ruf, 1999; Russo et al. 2001). Abundant experimental and clinical evidence indicates that alcohol affects platelet functions (Lacoste et al. 2001). Our results open up the important possibility that the ability of wine intake to attenuate thrombotic reactivity may be related not mainly to alcohol, but primarily to phenolic compounds such as (+)-catechin and/or others contained in the red wine extract. Indeed, alcohol alone had no significant antithrombotic effect in our model. Nevertheless, we cannot exclude an adjuvant influence of alcohol on the effects of phenolic compounds.

Platelet counts were moderately reduced in mice of both strains consuming alcohol-containing drinks. This effect is well documented for excessive alcohol consumption (Ballard, 1989). Except in apoE ${ }^{-1-}$ mice given RWE-alcohol, which had moderately increased platelet counts, the addition of phenols did not influence the alcohol-reducing effect. Thus, the antithrombotic effect associated with phenol intake is probably ascribable to an action on platelet functions, rather than on platelet counts.

$(+)$-Catechin was measurable in plasma from the wildtype and apoE $\mathrm{E}^{-1-}$ mice given CAT-alcohol or RWE-alcohol, proving that $(+)$-catechin was absorbed through the intestinal barrier and was available for exerting biological activities in blood and tissues. Plasma $(+)$-catechin levels were similar in the CAT-alcohol and RWE-alcohol groups, although the CAT-alcohol drink provided five times more $(+)$-catechin than did the RWE-alcohol. This is consistent with a saturable absorption mechanism and/or tissue storage. Kim et al. (2000) have shown that substantial amounts of (-)-epicatechin were recovered in tissues from rats given green tea. In our animals, tissue storage of $(+)$-catechin may have occurred and was perhaps more marked in the groups given the highest $(+)$-catechin concentration, i.e. the CAT-alcohol group. Alternatively, the proanthocyanidin dimers contained in RWE may have split into monomers in the gut mucosa. After perfusion of isolated rat small intestine with procyanidin dimers B2 (epicatechin-(4ß-8)-epicatechin) or B5 
(epicatechin-(4ß-6)-epicatechin), large amounts of (-)-epicatechin monomers are detected on the serosal side (Spencer et al. 2001). These ex vivo results were confirmed by an in vivo study (Baba et al. 2002) showing (-)-epicatechin in plasma from rats previously given oral procyanidin B2.

In conclusion, the present data from apoE $\mathrm{E}^{-/-}$mice indicate that wine polyphenols are absorbed following ingestion via an alcohol-containing drink that reproduces the alcohol concentration of natural wine. Mice supported by this sole type of beverage developed similar or slightly increased atherosclerotic lesions compared with controls mice while they expressed a decreased thrombotic reaction. The antithrombotic effect appears to depend on wine phenols and not on alcohol, and its occurrence in a model of arterial thrombosis suggests that it may be mediated, at least partly, by platelet inhibition, in keeping with data showing an anti-aggregating effect of wine intake on platelets from human volunteers (Ruf, 1999; de Lorgeril \& Salen, 1999; de Gaetano et al. 2002).

\section{Acknowledgements}

We are grateful to Mr José Durao for expert technical assistance with animal care.

\section{References}

Andre P, Arbeille B, Drouet V, Hainaud P, Bal dit Sollier C, Caen JP \& Drouet LO (1996) Optimal antagonism of GPIIb/IIIa favors platelet adhesion by inhibiting thrombus growth. An ex vivo capillary perfusion chamber study in the guinea pig. Arterioscler Thromb Vasc Biol 16, 56-63.

Andriambeloson E, Magnier C, Haan-Archipoff G, Lobstein A, Anton R, Beretz A, Stoclet JC \& Andriantsitohaina R (1998) Natural dietary polyphenolic compounds cause endothelium-dependent vasorelaxation in rat thoracic aorta. J Nutr 128, 2324-2333.

Aviram M (1983) Plasma lipoprotein separation by discontinuous density gradient ultracentrifugation in hyperlipoproteinemic patients. Biochem Med 30, 111-118.

Baba S, Osakabe N, Natsume M \& Terao J (2002) Absorption and urinary excretion of procyanidin B2 [epicatechin-(4ß-8)-epicatechin] in rats. Free Radic Biol Med 33, 142-148.

Ballard HS (1989) Hematological complications of alcoholism. Alcohol Clin Exp Res 13, 706-720.

Bentzon JF, Skovenborg E, Hansen C, Moller J, de Gaulejac NS, Proch J \& Falk E (2001) Red wine does not reduce mature atherosclerosis in apolipoprotein E-deficient mice. Circulation 103, $1681-1687$.

Booyse FM \& Parks DA (2001) Moderate wine and alcohol consumption: beneficial effects on cardiovascular disease. Thromb Haemost 86, $517-528$.

Carando S, Teissedre PL \& Cabanis JC (1998) Comparison of (+)catechin determination in human plasma by high-performance liquid chromatography with two types of detection: fluorescence and ultraviolet. J Chromatogr B Biomed Sci Appl 707, 195-201.

Carando S, Teissedre PL, Pascual-Martinez L \& Cabanis JC (1999) Levels of flavan-3-ols in French wines. J Agric Food Chem 47, 4161-4166.

Crespy V \& Williamson G (2004) A review of the health effects of green tea catechins in in vivo animal models. J Nutr 134, Suppl., 3431S-3440S

da Luz PL, Serrano Junior CV, Chacra AP, Monteiro HP, Yoshida VM, Furtado M, Ferreira S, Gutierrez P \& Pileggi F (1999) The effect of red wine on experimental atherosclerosis: lipid-independent protection. Exp Mol Pathol 65, 150-159.

de Gaetano G, De Curtis A, di Castelnuovo A, Donati MB, Iacoviello L \& Rotondo S (2002) Antithrombotic effect of polyphenols in experimental models: a mechanism of reduced vascular risk by moderate wine consumption. Ann N Y Acad Sci 957, 174-188.

de Lorgeril M \& Salen P (1999) Wine ethanol, platelets, and Mediterranean diet. Lancet 353, 1067.

Demrow HS, Slane PR \& Folts JD (1995) Administration of wine and grape juice inhibits in vivo platelet activity and thrombosis in stenosed canine coronary arteries. Circulation 91, 1182-1188.

Diaz J, Serrano E, Acosta F \& Carbonell LF (1998) Reference intervals for four biochemistry analytes in plasma for evaluating oxidative stress and lipid peroxidation in human plasma. Clin Chem 44, 2215-2217.

Emeson EE, Manaves V, Singer T \& Tabesh M (1995) Chronic alcohol feeding inhibits atherogenesis in C57BL/6 hyperlipidemic mice. Am J Pathol 147, 1749-1758.

Erba D, Riso P, Bordoni A, Foti P, Biagi PL \& Testolin G (2005) Effectiveness of moderate green tea consumption on antioxidative status and plasma lipid profile in humans. J Nutr Biochem 16, 144-149.

Franke AA \& Custer LJ (1994) High-performance liquid chromatographic assay of isoflavonoids and coumestrol from human urine. J Chromatogr B Biomed Appl 662, 47-60.

Fuhrman B, Volkova N, Coleman R \& Aviram M (2005) Grape powder polyphenols attenuate atherosclerosis development in apolipoprotein E deficient (E0) mice and reduce macrophage atherogenicity. J Nutr 135, 722-728.

Giovannoni G, Land JM, Keir G, Thompson EJ \& Heales SJ (1997) Adaptation of the nitrate reductase and Griess reaction methods for the measurement of serum nitrate plus nitrite levels. Ann Clin Biochem 34, 193-198.

Goto Y, Kikuchi H, Abe K, Nagahashi Y \& Oira S (1974) The effect of ethanol on the onset of experimental atherosclerosis. Tohoku $J$ Exp Med 114, 35-43.

Grassi D, Necozione S, Lippi C, Croce G, Valeri L, Pasqualetti P, Desideri G, Blumberg JB \& Ferri C (2005) Cocoa reduces blood pressure and insulin resistance and improves endotheliumdependent vasodilation in hypertensives. Hypertension 46, 398-405.

Hayek T, Fuhrman B, Vaya J, Rosenblat M, Belinky P, Coleman R, Elis A \& Aviram M (1997) Reduced progression of atherosclerosis in apolipoprotein E-deficient mice following consumption of red wine, or its polyphenols quercetin or catechin, is associated with reduced susceptibility of LDL to oxidation and aggregation. Arterioscler Thromb Vasc Biol 17, 2744-2752.

Johnson JL \& Jackson CL (2001) Atherosclerotic plaque rupture in the apolipoprotein E knockout mouse. Atherosclerosis 154, 399-406.

Keen CL, Holt RR, Oteiza PI, Fraga CG \& Schmitz HH (2005) Cocoa antioxidants and cardiovascular health. Am J Clin Nutr 81, Suppl., 298S-303S.

Kim S, Lee MJ, Hong J, Li C, Smith TJ, Yang GY, Seril DN \& Yang CS (2000) Plasma and tissue levels of tea catechins in rats and mice during chronic consumption of green tea polyphenols. Nutr Cancer 37, 41-48.

Klurfeld DM \& Kritchevsky D (1981) Differential effects of alcoholic beverages on experimental atherosclerosis in rabbits. Exp Mol Pathol 34, 62-71.

Kurosawa T, Itoh F, Nozaki A, Nakano Y, Katsuda S, Osakabe N, Tsubone H, Kondo K \& Itakura H (2005) Suppressive effect of cocoa powder on atherosclerosis in Kurosawa and Kusanagihypercholesterolemic rabbits. J Atheroscler Thromb 12, 20-28.

Lacoste L, Hung J \& Lam JY (2001) Acute and delayed antithrombotic effects of alcohol in humans. Am J Cardiol 87, 82-85. 
Leikert JF, Rathel TR, Wohlfart P, Cheynier V, Vollmar AM \& Dirsch VM (2002) Red wine polyphenols enhance endothelial nitric oxide synthase expression and subsequent nitric oxide release from endothelial cells. Circulation 106, 1614-1617.

Lopez-Jaramillo P \& Casas JP (2002) Blockade of endothelial enzymes: new therapeutic targets. J Hum Hypertens 16, Suppl., S100-S103.

Lowry OH, Rosebrough NJ, Farr AL \& Randall RJ (1951) Protein measurement with the folin phenol reagent. J Biol Chem 193, $1831-1841$.

Maor I, Hayek T, Coleman R \& Aviram M (1997) Plasma LDL oxidation leads to its aggregation in the atherosclerotic apolipoprotein E-deficient mice. Arterioscler Thromb Vasc Biol 17, 2995-3005.

Meagher E \& Rader DJ (2001) Antioxidant therapy and atherosclerosis: animal and human studies. Trends Cardiovasc Med 11, $162-165$.

Moghadasian MH, McManus BM, Godin DV, Rodrigues B \& Frohlich JJ (1999) Proatherogenic and antiatherogenic effects of probucol and phytosterols in apolipoprotein E-deficient mice: possible mechanisms of action. Circulation 99, 1733-1739.

Munday JS, Thompson KG, James KA \& Manktelow BW (1999) The effect of moderate alcohol consumption as either red or white wine in the C57BL/6 mouse atherosclerosis model. Coron Artery Dis 10, 97-102.

Murray CJ \& Lopez AD (1997) Mortality by cause for eight regions of the world: Global Burden of Disease Study. Lancet 349 , $1269-1276$.

Oemar BS, Tschudi MR, Godoy N, Brovkovich V, Malinski T \& Luscher TF (1998) Reduced endothelial nitric oxide synthase expression and production in human atherosclerosis. Circulation 97, 2494-2498.

Osman HE, Maalej N, Shanmuganayagam D \& Folts JD (1998) Grape juice but not orange or grapefruit juice inhibits platelet activity in dogs and monkeys. J Nutr 128, 2307-2312.

Pace-Asciak CR, Hahn S, Diamandis EP, Soleas G \& Goldberg DM (1995) The red wine phenolics trans-resveratrol and quercetin block human platelet aggregation and eicosanoid synthesis: implications for protection against coronary heart disease. Clin Chim Acta 235, 207-219.

Plump AS, Smith JD, Hayek T, Aalto-Setala K, Walsh A, Verstuyft JG, Rubin EM \& Breslow JL (1992) Severe hypercholesterolemia and atherosclerosis in apolipoprotein E-deficient mice created by homologous recombination in ES cells. Cell 71, 343-353.

Pratico D, Tangirala RK, Rader DJ, Rokach J \& FitzGerald GA (1998) Vitamin E suppresses isoprostane generation in vivo and reduces atherosclerosis in apoE-deficient mice. Nat Med 4, 1189-1192.

Rah DK, Han DW, Baek HS, Hyon SH \& Park JC (2005) Prevention of reactive oxygen species-induced oxidative stress in human microvascular endothelial cells by green tea polyphenol. Toxicol Lett 155, 269-275.

Reddick RL, Zhang SH \& Maeda N (1994) Atherosclerosis in mice lacking apo E. Evaluation of lesional development and progression. Arterioscler Thromb 14, 141-147.
Ruf JC (1999) Wine and polyphenols related to platelet aggregation and atherothrombosis. Drugs Exp Clin Res 25, 125-131.

Russo P, Tedesco I, Russo M, Russo GL, Venezia A \& Cicala C (2001) Effects of de-alcoholated red wine and its phenolic fractions on platelet aggregation. Nutr Metab Cardiovasc Dis 11, 25-29.

Sano J, Inami S, Seimiya K, Ohba T, Sakai S, Takano T \& Mizuno K (2004) Effects of green tea intake on the development of coronary artery disease. Circ J 68, 665-670.

Shaish A, Pape M, Rea T, Srivastava RA, Latour MA, Hopkins D \& Schonfeld G (1997) Alcohol increases plasma levels of cholesterol diet-induced atherogenic lipoproteins and aortic atherosclerosis in rabbits. Arterioscler Thromb Vasc Biol 17, 1091-1097.

Spencer JP, Schroeter H, Shenoy B, Srai SK, Debnam ES \& Rice-Evans C (2001) Epicatechin is the primary bioavailable form of the procyanidin dimers B2 and B5 after transfer across the small intestine. Biochem Biophys Res Commun 285, $588-593$.

Sung H, Min WK, Lee W, Chun S, Park H, Lee YW, Jang S \& Lee DH (2005) The effects of green tea ingestion over four weeks on atherosclerotic markers. Ann Clin Biochem 42, 292-297.

Suzuki J, Ogawa M, Izawa A, Sagesaka YM \& Isobe M (2005) Dietary consumption of green tea catechins attenuate hyperlipidaemiainduced atherosclerosis and systemic organ damage in mice. Acta Cardiol 60, 271-276.

Tangirala RK, Casanada F, Miller E, Witztum JL, Steinberg D \& Palinski W (1995a) Effect of the antioxidant $N, N^{\prime}$-diphenyl-1,4phenylenediamine (DPPD) on atherosclerosis in apoE-deficient mice. Arterioscler Thromb Vasc Biol 15, 1625-1630.

Tangirala RK, Rubin EM \& Palinski W (1995b) Quantitation of atherosclerosis in murine models: correlation between lesions in the aortic origin and in the entire aorta, and differences in the extent of lesions between sexes in LDL receptordeficient and apolipoprotein E-deficient mice. J Lipid Res 36, $2320-2328$.

Vinson JA, Teufel K \& Wu N (2004) Green and black teas inhibit atherosclerosis by lipid, antioxidant, and fibrinolytic mechanisms. J Agric Food Chem 52, 3661-3665.

Wollny T, Aiello L, Di Tommaso D, Bellavia V, Rotilio D, Donati MB, de Gaetano G \& Iacoviello L (1999) Modulation of haemostatic function and prevention of experimental thrombosis by red wine in rats: a role for increased nitric oxide production. $\mathrm{Br} \mathrm{J}$ Pharmacol 127, 747-755.

Yamakoshi J, Kataoka S, Koga T \& Ariga T (1999) Proanthocyanidin-rich extract from grape seeds attenuates the development of aortic atherosclerosis in cholesterol-fed rabbits. Atherosclerosis 142, 139-149.

Zhang SH, Reddick RL, Avdievich E, Surles LK, Jones RG, Reynolds JB, Quarfordt SH \& Maeda N (1997) Paradoxical enhancement of atherosclerosis by probucol treatment in apolipoprotein E-deficient mice. J Clin Invest 99, 2858-2866.

Zhang SH, Reddick RL, Piedrahita JA \& Maeda N (1992) Spontaneous hypercholesterolemia and arterial lesions in mice lacking apolipoprotein E. Science 258, 468-471. 